\title{
THE PROBLEM OF SEARCH SAFE AND EFFECTIVE METHOD IN REDUCING INJURIES IN BODYBUILDING STAGE OF SPECIALIZED BASIC TRAINING
}

Slavityak O.S.

Nikolayev National University

\begin{abstract}
Annotation. Purpose: To identify the most frequently used coaches and athletes in bodybuilding principles that can help to reduce the injuries of athletes while maintaining the progressivity results. Material: a survey participated 86 coaches and 120 athletes, bodybuilders from 5 to 8 years. Results: It was found that most of the coaches used in the course of employment principles generally accepted system of training. In such circumstances, the risk of injury to athletes is large enough. When using pre-exhaustion principle to increase the intensity of the training process increases the risk of overloading the body athletes. Conclusions: Athletes with a longer training experience (about 8 years), more likely to use the principle of prior exhaustion. In this case athletes try using this principle to reduce the operating parameters of volume load. This helps to reduce the level of injury and maintain positive dynamics performance.
\end{abstract}

Keywords: training, specialized, basic, fatigue, bodybuilding, injuries, fitness.

\section{Introduction}

The development of a modern bodybuilding requires new methods of training process optimization which allow to lower a traumatism level. The importance of this problem solution is connected with continuous increase of physical activities that at systematic use considerably increases the traumatism level in the course of training activity [5, $7,8,9,10]$.

According to information from the leading world bodybuilding trainers and also the scientists specializing in this area $[7,10,11]$, it is established that approximately $68,3 \%$ of accidents in bodybuilding occur at a stage of a specialized basic training. This circumstance confirms the fact that exactly at this stage of a long-term training maximum and extreme strength training, mainly anaerobic type, necessary for a "rough" set of muscles, are generally used, that quite often promotes the increase of a traumatism level in a sport $[9,10]$.

At the same time, in the process of bodybuilding development, the attempts of training process optimization were made to lower the traumatism level in this kind of sport, but the main solutions of this problem were only the decrease of amount and intensity of physical activities that not always positively influenced the growth of athletes efficiency $[1,8]$. Even so, the use of basic and isolating exercises in the process of athletes training, and also values of size of their influence on effectiviness level, especially at a stage of a specialized basic training in bodybuilding, are studied insufficiently.

Work is performed within the research work scope of the Olympic and professional sport department at the Petro Mohyla Black Sea State university "Variability of training work indicators in bodybuilding and their influence on dynamics of athletes organism functional condition", number of the state registration 0109 U004555.

Purpose, tasks of the work, material and methods

The purpose of research is determination of most often used training principles in bodybuilding which allow to reduce traumatism level as much as possible, saving progressiveness of the results.

Methods, organization of researches.

86 trainers and 120 bodybuilders aged 22-24 years (experience in bodybuilding - 5 and 8 years) from Nikolaev took part in the survey. The survey was carried out to achieve the goal. Participants answered such questions: what training principles in bodybuilding allow to reduce traumatism level of athletes, what stage of a long-term training is the most traumatic, what training methods allow to have against progressiveness of results a minimum traumatism level among athletes, most often used training principles at the stage of a specialized basic training, in what cases and at what stages of a long-term training the principle of preliminary exhaustion is used?

\section{Results of the researches} figures $1-4$.

Primary results of the survey were subjected to general and statistical calculations and graphically displayed in

In fig. 1. the results of the survey which allow to determine the preference of training principles usage not only for efficiency increase, but also for lowering traumatism level are displayed. 




Fig. 1. The training principles which are used to lower traumatism level at the stage of a specialized basic training, $n=206$

The analysis of the survey results testifies that a significant amount of the trainers $(38,4 \%)$ consider that the use of the principle of a pyramid during trainings will promote the increase of fitness level against a low rate of traumatism. However, only $5,2 \%$ of the trainers consider that the positive solution of this problem in bodybuilding can be promoted by application in the process of training the principle of preliminary exhaustion.

The results of the survey among athletes (experience in bodybuilding is about 5 years) show almost similar answers to the questions among trainers.

In turn, despite the identity of the survey results among trainers and athletes, the group of athletes (experience in bodybuilding is more than 8 years) show completely opposite answers to the questions.

This circumstance testifies that in connection with growth of fitness level athletes begin to search new ways of training process optimization. One of the main directions of this search is the use mainly those training principles which allow to reach the maximum dynamics of results without significant extension of physical activity, and to lower traumatism level in bodybuilding.

Modern requirements for the training process of athletes in bodybuilding demand not only maximum results at a certain stage, but also possibility of its increase throughout a long-term competitive activity [1, 7, 10]. At the same time, the achievement of a long-term positive dynamics of results is possible only on a low traumatism level and the high level of adaptation processes that isn't practically possible without the use of non-standard (specific) methods, principles and means of training [7,9].

One of the most specific and at the same time low-studied training principles in strength sports is the principle of preliminary exhaustion. At the same time the question concerning efficiency and need of its use by trainers and athletes in bodybuilding, especially at the stage of a specialized basic training, was not practically studied.

In fig. 2. the results of the survey allowing to determine frequency and nature of the principle of preliminary exhaustion use in training activity at the stage of a specialized basic training are graphically displayed.

The analysis of the survey results testifies that $72,1 \%$ of trainers and $76 \%$ of athletes (experience in bodybuilding is about 5 years ) don't use the principle of preliminary exhaustion in training. At the same time, among athletes (experience in bodybuilding is more than 8 years) - only $27,7 \%$ of participants don't use this training principle in weight training. 




Fig. 2. Features of the principle of preliminary exhaustion use by trainers and athletes in bodybuilding at the stage of a specialized basic training (according to the survey results), $n=206$

Thus, on the basis of the results analysis it is possible to assume that with the experience increase in bodybuilding (after 7-8 years of trainings) most athletes start using specialized principles in training on another way (they rely more on their own knowledge and feelings than on trainers experience) that fully changes the general system of the training activity.

The applications of techniques in bodybuilding is caused by the need of solution of training and competitive activity problems, connected not only with the lack of efficiency, but also with specific features of changes adaptation in athletes organism and possible negative consequences of inadequate weight training (big level of traumatism).

The definition of origin of the principle of preliminary exhaustion use by trainers and athletes in bodybuilding at the stage of a specialized basic training allows to understand and adjust the mechanism of training activity management more precisely (fig.3).

However the analysis of the survey results testifies that opinions of its participants concerning the need of the principle of preliminary exhaustion at this stage of training are rather contradictory. So, 40,4\% of athletes (experience in bodybuilding is about 5 years) and $31,1 \%$ of trainers consider that this principle needs to be used only in the conditions of positive dynamics lack throughout a long period. About $32 \%$ of this contingent is sure that this principle is needed only to solve the problem of the intensity of training process increase.

In turn, the results in a group of athletes (experience in bodybuilding is more than 8 years) testifies that the principle of preliminary exhaustion is needed only to solve the problem of gap in the development of a certain muscle group $(45,9 \%)$. Thus, only $9,4 \%$ consider that this principle needs to be used only in conditions of insufficient level of training process intensity.

Thus, the results indicate the need to carry out more profound and prolonged complex researches concerning expediency and efficiency of this training principle use at the stage of a specialized basic training, and also for athletes with various experience in bodybuilding.

In modern system of bodybuilding some types of the principle of preliminary exhaustion are used depending on the purposes and problems of training process, an athlete level of proficiency and his individual function capabilities of an organism. Mainly, two most widespread options of preliminary exhaustion are used in the training activity at the stage of a specialized basic training. In the first case, series of the isolating exercise and then the basic one are carried out at the beginning. In the second case, sets of the isolating and basic exercises alternate without rest intervals between them. 




Fig. 3. The main reasons for application of the principle of preliminary exhaustion by trainers and athletes in bodybuilding at the stage of a specialized basic training (according to the survey results), $n=206$

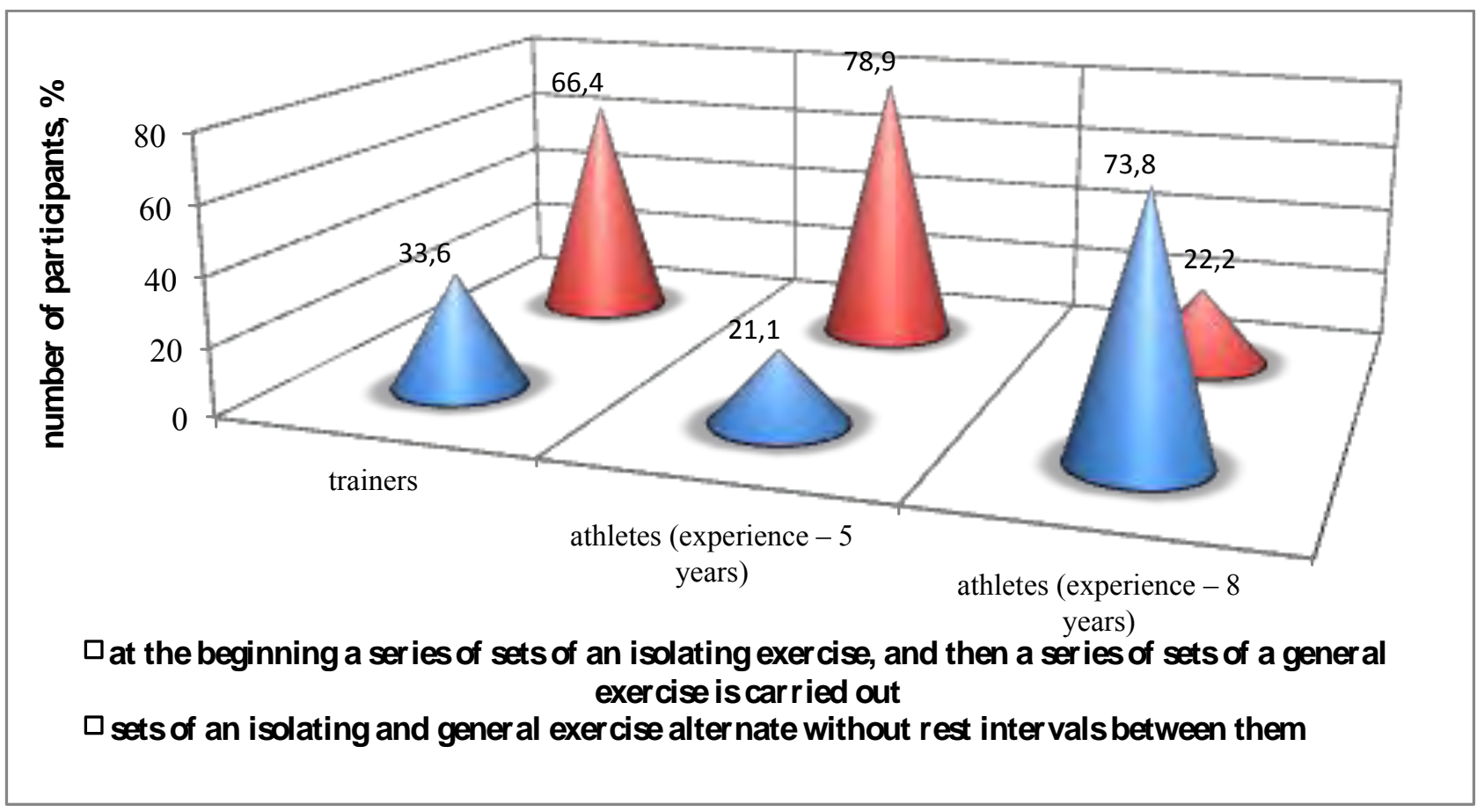

Fig. 4. Types of preliminary exhaustion and the level of its use by trainers and athletes in bodybuilding at the stage of a specialized basic training (according to the survey results), $n=206$

In fig. 4 results of the survey allowing to establish the preferences of use of the principle of preliminary exhaustion in the course of training by participants are displayed.

The analysis of the received results testifies that $66,4 \%$ of trainers and $78,9 \%$ of athletes (experience in bodybuilding is about 5 years) mainly use the most intensive type of preliminary exhaustion in training (sets of the 
isolating and basic exercises alternate without rest intervals between them). However, among athletes (experience in bodybuilding is more than 8 years) -the type of principle of preliminary exhaustion based on the scheme of the primary one - is carried out a series of sets of isolating exercise, and then a series of a general exercise on a certain muscle group is used frequently $(73,8 \%)$.

This fact specifies that more experienced athletes (experience in bodybuilding is about 8 years) at the beginning of training try to tire the main working muscle group due to initial performance of a series of isolating exercise sets. As a result of such exhaustion, while performing general exercise, the working weight of burdening will be decreased by at least $20 \%$ that will allow to reduce also traumatism level during weight training. Unfortunately the use of an intensive type of preliminary exhaustion (sets of the isolating and basic exercises alternate without rest intervals between them), especially at the stage of a specialized basic training during intensive weight training, promotes the increase of athletes traumatism level due to rather high intensity of work at total lack of rehabilitation periods between sets.

\section{Conclusions}

1. It is determined that most of trainers at the stage of a specialized basic training use a standard system of the training principles with a great traumatism level. Even so, in those insignificant cases when trainers try to use the principle of preliminary exhaustion during training to increase the intensity of a training process, it only increases the risk of an organism overload.

2. It is revealed that athletes (experience in bodybuilding is more than 8 years) compared with other participants of the survey, not only use the principle of preliminary exhaustion frequently, but also try to reduce physical activity by means of this principle that will allow to lower the traumatism level keeping positive dynamics of efficiency.

Prospects of further researches. The lack of information in scientific and methodical literature concerning efficiency and expediency of the principle of preliminary exhaustion use at the stage of a specialized basic training, doesn't allow to determine accurately the possibility of training process optimization for a long-term dynamics of efficiency growth in the conditions of burdening reduction in general exercises at the expense of preliminary training of working muscle group by the isolating exercise. Correspondingly, the prospect of the principle of preliminary exhaustion complex use at this stage of training, will give the chance to reduce training physical activities keeping positive dynamics results, and also will allow to minimize the risk of pathological processes development in the conditions of muscle tension. The solution of these questions will give the chance for scientific justification of planning, control and management of a long-term training process in bodybuilding.

\section{References:}

1. Vejder D. Sistema stroitel'stva tela [The system of construction of the body], Moscow, Physical Culture and Sport, 1991, $112 \mathrm{p}$

2. Bondarchuk A.P. Upravlenie trenirovochnym processom sportsmenov vysokogo klassa [Management training process high-class athletes], Moscow, Olympia Press, 2007, 272 p.

3. Vorob'ev A.N., Sorokin Iu.K. Anatomiia sily [Anatomy of force], Moscow, Physical Culture and Sport, 1980,178 p.

4. Vorob'ev A.N. Trenirovka, rabotosposobnost', reabilitaciia [Training, operability, rehabilitation], Moscow, Physical Culture and Sport, 1989, 272 p.

5. Gordon S.M. Sportivnaia trenirovka [Sports training], Moscow, Physical Culture and Sport, 2008,256 p.

6. Laputin A.N. Atleticheskaia gimnastika [Athletic gymnastics], Kiev, Health, 1990, 176 p.

7. Matveev L. P. Osnovy obshchej teorii sporta i sistemy podgotovki sportsmenov [The general theory of sport and the system of training athletes], Kiev, Olympic Literature, 1999, 320 p.

8. Oleshko V.G. Pidgotovka sportsmeniv u silovikh vidakh sportu [Training athletes in power sports], Kiev, DIA, 2011, 443 p.

9. Platonov V.N. Sistema podgotovki sportsmenov v olimpijskom sporte [The system of preparation of sportsmen in Olympic sport], Kiev, Olympic Literature, 2004, 808 p.

10. Khartman Iu., Tiunnemann Kh. Sovremennaia silovaia trenirovka [Modern strength training], Berlin, Shtortferlag, $1988,335 \mathrm{p}$

11. Chernozub A.A. Pedagogika, psihologia ta mediko-biologicni problemi fizicnogo vihovanna i sportu [Pedagogics, psychology, medical-biological problems of physical training and sports], 2012, vol.8, pp. $114-120$.

12. Chernozub A.A. Peculiarities of cortisol level changes in the blood of athletes and untrained boys in response to heavy power training loads. European International Journal of Science and Technology. 2013, vol.2(9), pp. 52 57.

13. Hatfield F.C. Bodybuilding a scientific approach Chicago. Contemporary book, 1984, 272 p.

14. Hatfield F.C. Hardcore Bodybuilding. Scientific Approach, McGraw-Hill., 1993, 448 p.

15. Tesch P.A. Training for Bodybuilding. Strength and power in Sport. Blackwell Scientific Publications, 1991, pp. $370-381$ 
Slavityak O. S.: ORCID: http://orcid.org/0000-0002-9779-7997; olegslavitjak88@gmail.com; Nikolayev National University; . Nicholas str., 24, Nikolaev, 54000, Ukraine.

Cite this article as: Slavityak O.S. The problem of search safe and effective method in reducing injuries in bodybuilding stage of specialized basic training. Physical education of students, 2014, vol.6, pp. 63-68. doi:10.15561/20755279.2014.0612

The electronic version of this article is the complete one and can be found online at: http://www.sportpedu.org.ua/html/arhive-e.html

This is an Open Access article distributed under the terms of the Creative Commons Attribution License, which permits unrestricted use, distribution, and reproduction in any medium, provided the original work is properly cited (http:// creativecommons.org/licenses/by/3.0/deed.en).

Received: 10.06 .2014

Published: 30.06 .2014 